\title{
Estimation of Bladder Pressure by using Poiseuilles Equation
}

\author{
F.N.AL-Doorie *
}

Date of acceptance 28/5/2006

\begin{abstract}
Poiseuilles equation is used to measure the bladder pressure, for healthy persons (not prostatics), instead of insertion a catheter (indirect method) or by direct method in which a needle is inserted through the wall of the abdomen directly into the bladder.(1)

The present study, poiseuilles law is used to measure bladder pressure and to determine the relationship between the volume, volume rate and pressure for twenty five volunteers in the range of 18-25 years by using this equation .
\end{abstract}

\section{Introductiond}

Several muscles, organs, and nerves are involved in collecting, storing, and releasing urine. The Kidneys form urine by filtering wastes and extra water from the bioodstream. The ureters are tubes that carry urine from the kidneys to bladder. Normal urine flow is one way. If urine back up toward the kidneys, infections are more likely.

The bladder, a hollow muscular organ shaped like a balloon, it stores urine. It swells into a round shape when it is full and gets smaller as it empties. A healthy bladder can hold up 16 ounces ( 2 cups) of urine comfortably for 2 to 5 hours.

The bladder opens into the urethra, the tube that allows urine to pass outside the body. Circular muscles called sphincters close tightly to keep urine from leaking.

When the bladder begins to fill with urine and reach its limit, at that point, nerves in the bladder send a massage to the brain. The brain signals the

* Medical Physics Department, College of Medicine, University of Baghdad sphincter muscles to relax. At the same time, the brain signals the bladder muscles to tighten, squeezing urine out. Urine can then leave the bladder through the urethra. When these signals occur in the correct order, normal urination occurs.(2)

Problems in the urinary system can be caused by aging, illness, or injury. The muscles in ureters, bladder, and urethra tend to become weaker with age.

At present the diagnosis of some voiding dysfunctions is based on an invasive investigation of the bladder, called a bladder pressure-flow analysis. The investigation is invasive, because catheters are inserted via the urethra in the bladder and in the rectum of the patient. A diagnosis can be made based on the two signals (bladder pressure and flow-rate) measured in this way. Although the invasive method is accurate, it is time consuming, expensive, and sometimes painful and unpleasant for the patient. Therefore non-invasive techniques have been 
introduced to avoid these inconveniences. The non-invasive external condiom catheter is one of these new techniques. ( 3 ), (7)

\section{Theory and method}

Poiseulles law states that, the flow through a given tube depends on the pressure difference from one end to the other, the length (L) of the pressure difference is doubled, and the flow also doubles. The flow rate varies inversely with the length and viscosity if either is doubled, the flow rate is reduced by one-half equation ( 1 ).

Poiseuille was related the strong dependence of the flow rate on the radius of the tube. That the flow rate is directly proportion to the forth power of the radius, $\left(Q \infty R^{4}\right)$ i.e. if the radius doubled the flow rate will increases by factor of $16\left(2^{4}\right)$. Poiseuilles equation was written as follow;

$Q=\frac{\left(P_{A}-P_{B}\right) \pi R^{4}}{8 \eta L}$.

Q Is the flow rate or volume per unit time.

$P_{A}-P_{B}$ is the difference in pressure.

$R$ Is the radius.

$\mathrm{L}$ Is the length $\eta \quad$ Is the viscosity of liquid.

$\pi$ is constant equal to 3,14

Twenty five healthy. subjects (all males) ranging age from $18-25$ years without symptoms of prostatic were studied. They have been asked to void in a measuring cylinder, in order to measure the volume of their urine. A stopwatch was used to measure urinating time. From these data the flow rate was calculated by dividing the urine volume over the collecting time. The radius and the length of pens were taken selectively having about the same as the average radius for the penal orifice which is $\left(1.5 \pm 0.2 * 10^{-3}\right.$ $\mathrm{m})$ and the length was chosen in the region of $0.15 \pm 0.05 \mathrm{~m}$, the average urine viscosity taken as the viscosity of water. These were applied and pressure was calculated by using equation (1).

\section{Results}

In the present work, we apply this simple method in healthy males. Twenty five volunteers in the range of 18-25 years. Each volunteer is studied three times. The results are shown in table (1).

Table (1): The volume and volume rate of urine samples

\begin{tabular}{|c|c|c|c|c|}
\hline $\mathrm{V}\left(\mathbf{m}^{3}\right)^{*} 10^{-6}$ & $\mathrm{~V} / \mathrm{t}\left(\mathrm{m}^{3} / \mathrm{S}\right)^{*} 10^{-6}$ & $\mathbf{P} \times 10^{-2} \mathrm{mH} 20$ & $\mathbf{P}\left(\mathrm{N} / \mathrm{m}^{2}\right)$ & Slope $=(\mathrm{V} / \mathrm{Pt})^{\star} \mathbf{~}^{-6}$ \\
\hline $110 \pm 5.2$ & $14 \pm 0.7$ & $10 \pm 1.2$ & $990 \pm 116$ & $0.0141 \pm 0.006$ \\
$160 \pm 6.1$ & $18.33 \pm 0.8$ & $13 \pm 1.8$ & $1274 \pm 176$ & $0.0143 \pm 0.0045$ \\
$200 \pm 7.2$ & $22.56 \pm 0.85$ & $16.2 \pm 1.6$ & $1568 \pm 156$ & $0.0143 \pm 0.005$ \\
$290 \pm 10$ & $29.61 \pm 1.02$ & $21.25 \pm 2.1$ & $2058 \pm 205$ & $0.0144 \pm 0.005$ \\
$340 \pm 15.4$ & $33.85 \pm 1.5$ & $24.3 \pm 1.5$ & $2352 \pm 147$ & $0.0143 \pm 0.010$ \\
$420 \pm 18.2$ & $38 \pm 1.65$ & $27.41 \pm 2.2$ & $2646 \pm 215$ & $0.0143 \pm 0.008$ \\
$485 \pm 20.1$ & $39.8 \pm 1.72$ & $28.2 \pm 2.1$ & $2763 \pm 205$ & $0.0144 \pm 0.0084$ \\
\hline
\end{tabular}

Fig (1) shows a typical pressure-volume curve for the baldder, which stretches as the volume increases. The rise in pressure is expected to be proportional to the volume. However, for a given increase in radius $(R)$ the volume increases as $\left(R^{3}\right)$ while the pressure only increases as a bout $\left(R^{2}\right)$. This relationship largely accounts for relatively low slope of the major portion of the pressure-volume curve. The volume is increased until reached the maximum value in the bladder before voiding $(500 \mathrm{ml})(1)$.

Fig (2) shows a plot of the rates of flow of urine against the pressure of the bladder in $\left(\mathrm{N} / \mathrm{m}^{2}\right)$. 


\section{Discussion}

Any procedure designed to provide information about a bladder problem can be called an urodynamic test. This test is the study of how the body stores and release urine. There are many methods used to study the function of the bladder such as uroflowmeter ,cystometrog ram(CMG) and others.(4) An uroflowmeter automatically measures the amount of urine and the flow rate. This equipment creates a graph that shows changes in flow rate from second to second so that it can see the peak flow rate and how many seconds it took to get there. Results of this test will be abnormal if the bladder muscle is weak or urine flow is obstructed.

A cystometrog ram (CMG) measures how much pressure build up inside the bladder as it stores urine. It is used to a catheter to empty the bladder completely. Then a special, smaller catheter with a pressure measuring tube called a cystometer will be used to fill the bladder slowly with warm water. The volume of water and the bladder pressure will be recorded. The catheter can measure the pressures required to urinate. This pressure flow study helps to identify bladder outlet obstruction that man may experience with prostate enlargement.

Urodynamic tests may be performed with or without equipment to take pictures of the bladder during filling and emptying. The imaging equipment may use X-rays or sound waves. If Xray equipment is used, the liquid used to fill the bladder may be a contrast medium that will show up on the Xray. The pictures show the size and shape of urinary tract.(5)

This study is a simple technique using a Poiseuilles equation to estimate the bladder pressure and flow rate of urine. The volume $(\mathrm{ml})$ of fluid expelled from the urethra each second, it is a reflection of bladder emptying, a noninvasive method used to screen the integrity of the bladder and its outlet during. The voided volume (volume of urine actually voided) was collected from the volunteers were asked to void three times with no catheter was used. This volume is considered $200-400 \mathrm{ml}$. Optimally, the setting for obtaining a uroflow should be conducive to the patient voiding as he normally does making an adequately private environment important.

In fig ( 3 ); the relationship between the flow rate and the volume is linear, it can therefore be concluded that using this simple method can be done by interrupting the flow-rate without interference with the remainder of the voiding. This result is corresponding to the results obtained by using the external catheter a non-invasive pressure measurement (3).

Poiseuilles law applies to rigid tubes of constant radius. Since the bladder has elastic walls, urine flow does not obey the law exactly. In addition the average urine viscosity was taken as the viscosity of water. The pressurevolume curve for bladder (Fig-1) indicated that the pressure depends on the volume in the bladder at the moment the flow rate was interrupted. This curve is corresponding to the typical pressure volume curve obtained by using invasive and non-invasive methods.(3),(5).

In Fig (2) shows a plot of the rates of urine against the pressure of the bladder. According to Poiseulles equation the relationship is straight line and the slope is equal to;

$$
\text { Slope }=\frac{V / t}{P}=\frac{R^{4} \pi}{8 \eta \mathrm{L}}
$$

This unlike prostatic man the value of this slope is less than the normal value due to:1- The pressure is very high $(100 \mathrm{~cm} \mathrm{H} 2 \mathrm{O})(1)$ about three times more than the maximum normal due to 
the constriction in the urine passage so that the volume rate of flow is low due to the small radius according to the Poiseuilles equation which shows that the volume rate is proportional with $\left(\mathrm{R}^{4}\right)$, radius to the power four, for the reason so the slope is low.2-in the normal person the type of flow is laminar in contrast to the prostatic case the flow is turbulent and the slope of the laminar is greater than that in turbulent flow. Mainly the given increase in the flow rate needs less pressure for the laminar flow rate than for turbulent flow rate. This means the laminar flow is more efficient than the turbulent (6).

The slope in the present work is equal to $(0.0142 \pm 0.0064)^{*} 10^{-6}$. I suggest for the further work to measure the bladder pressure for prostatic men by using this method, which is painless and easy to use.

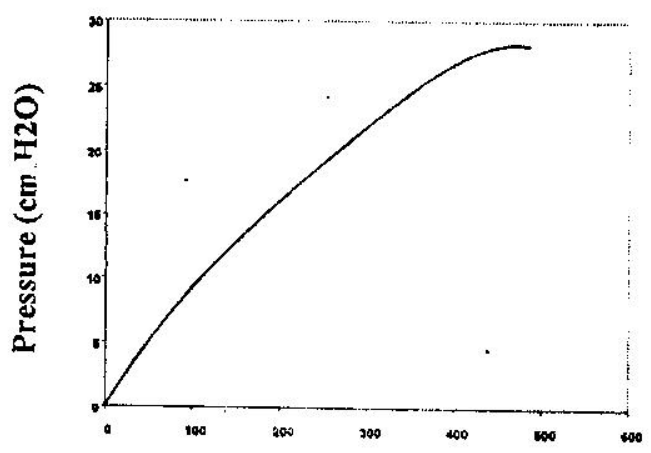

Volume (mI)

Fig-1- The typicaly pressure-volume relationship in the urinary bladder

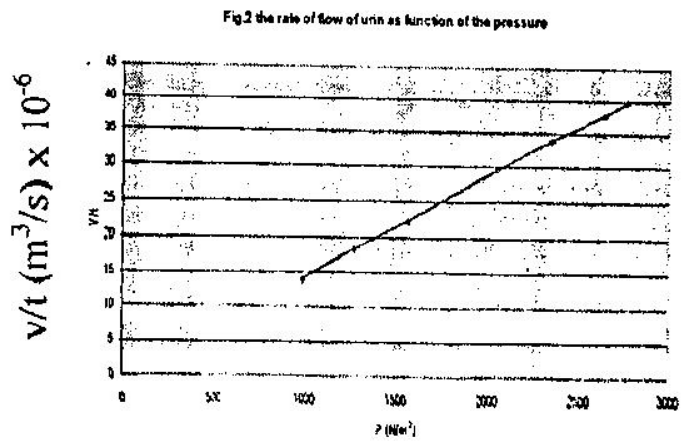

Fig-2- The rate of flow of urine $V / t$ $\left(\mathrm{m}^{3} / \mathrm{s}\right)$ as function of the pressure $\mathrm{P}\left(\mathrm{N} / \mathrm{m}^{2}\right)$

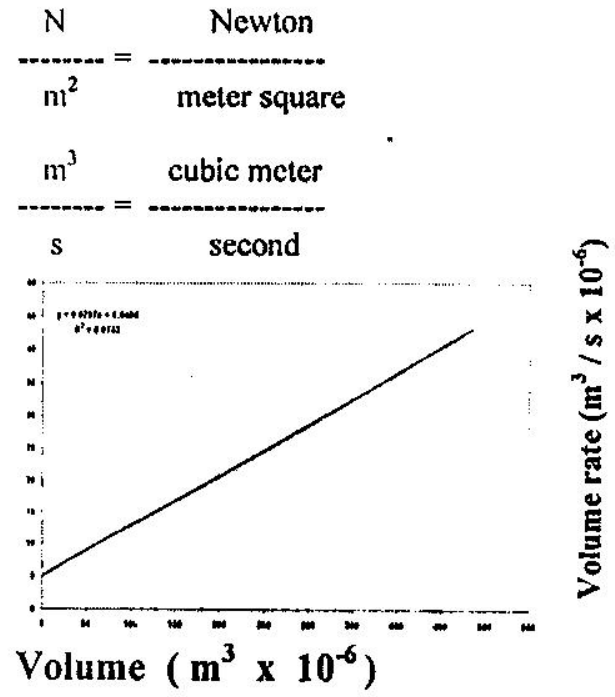

Fig-3 the relationship between volume and volume rate

\section{References}

1. Cameron, J.R \& Skofronick, J.G Medical Physics ,P.104.Copy right e 1978 by John wiley and Sons.Inc .

2. Keele,C.A \& Neil, E. Samson Wrights, Applied physiology, 1972 .

3. R Van Mastright. Non-Invasive Bladder measurement,2004 http;//www.erasumusmc.nV/facu 1 teit/index htm.

4. National kidney and urologic Disease Information

Clearinghouse. hitp://www.a fud.Org/.

5. Urolology-urodynamic homepage. http://www2.eur.nL/FGG/UDU/i ndex.htm.

6. Burns,D.M \& Macdonald,S.G Physics for Biology \& premedical Students, 1975.

7. Brocklehurst,J.C. Noncatheter devices for urinary incontinence in the elderly Medical instrumentation .Vol.16(3), 1982. 
استخدام معادلة بوازيل لتقييم ضنط المثائة

"فلاح ناجي نامق خضر الدوري

* فيزياء طبية، جامعة بذاد//كلية الطب، فرع الفزيولوجي/شعبة الفيزياء الطبية

الخلاصة:-

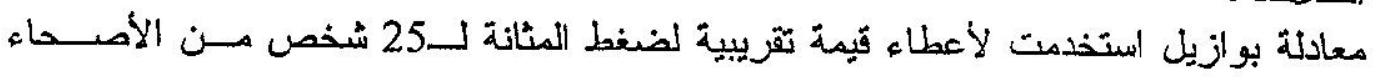

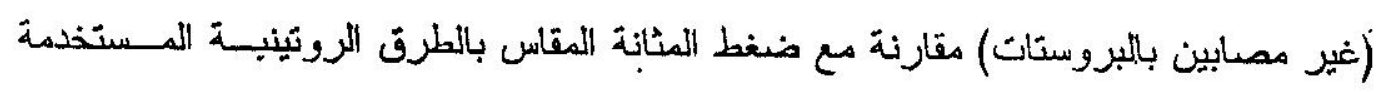

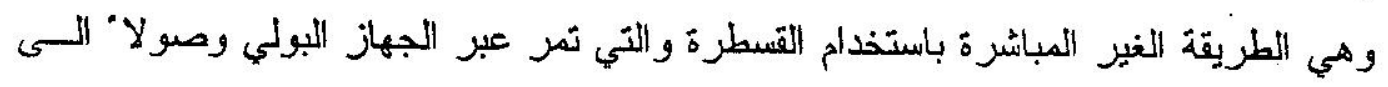

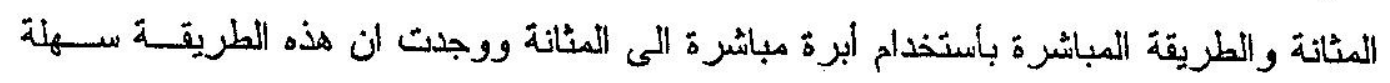
ورخيصة الثمن وغير مؤذية للمريض . 